University of Nebraska - Lincoln

DigitalCommons@University of Nebraska - Lincoln

Robert G. Fuller Publications and Presentations Research Papers in Physics and Astronomy

May 1998

\title{
Nobel prize winners in physics from 1901 to 1990: Simple statistics for physics teachers
}

Weijia Zhang

Arizona State University

Robert Fuller

rfuller@neb.rr.com

Follow this and additional works at: https://digitalcommons.unl.edu/physicsfuller

Part of the Physics Commons

Zhang, Weijia and Fuller, Robert, "Nobel prize winners in physics from 1901 to 1990: Simple statistics for physics teachers" (1998). Robert G. Fuller Publications and Presentations. 23.

https://digitalcommons.unl.edu/physicsfuller/23

This Article is brought to you for free and open access by the Research Papers in Physics and Astronomy at DigitalCommons@University of Nebraska - Lincoln. It has been accepted for inclusion in Robert G. Fuller Publications and Presentations by an authorized administrator of DigitalCommons@University of Nebraska - Lincoln. 


\title{
Nobel prize winners in physics from 1901 to 1990: \\ Simple statistics for physics teachers
}

\author{
Weijia Zhang \\ Department of Physics and Astronomy, Arizona State University \\ Robert G. Fuller \\ Department of Physics and Astronomy, University of Nebraska-Lincoln
}

\begin{abstract}
A demographic database for the 139 Nobel prize winners in physics from 1901 to 1990 has been created from a variety of sources. The results of our statistical study are discussed in the light of the implications for physics teaching.
\end{abstract}

The Nobel prize in physics, established in 1901 by Alfred Nobel, aimed to reward "the person who shall have made the most important discovery or invention in the domain of Physics" [1]. This century's physics development is reflected by the priz- es awarded to Nobel laureates [2]. The Nobel laureates are among the most talented, successful and fortunate scientists of thousands of researchers. Besides public recognition for their contribution in the scientific domain, Nobel laureates can play 


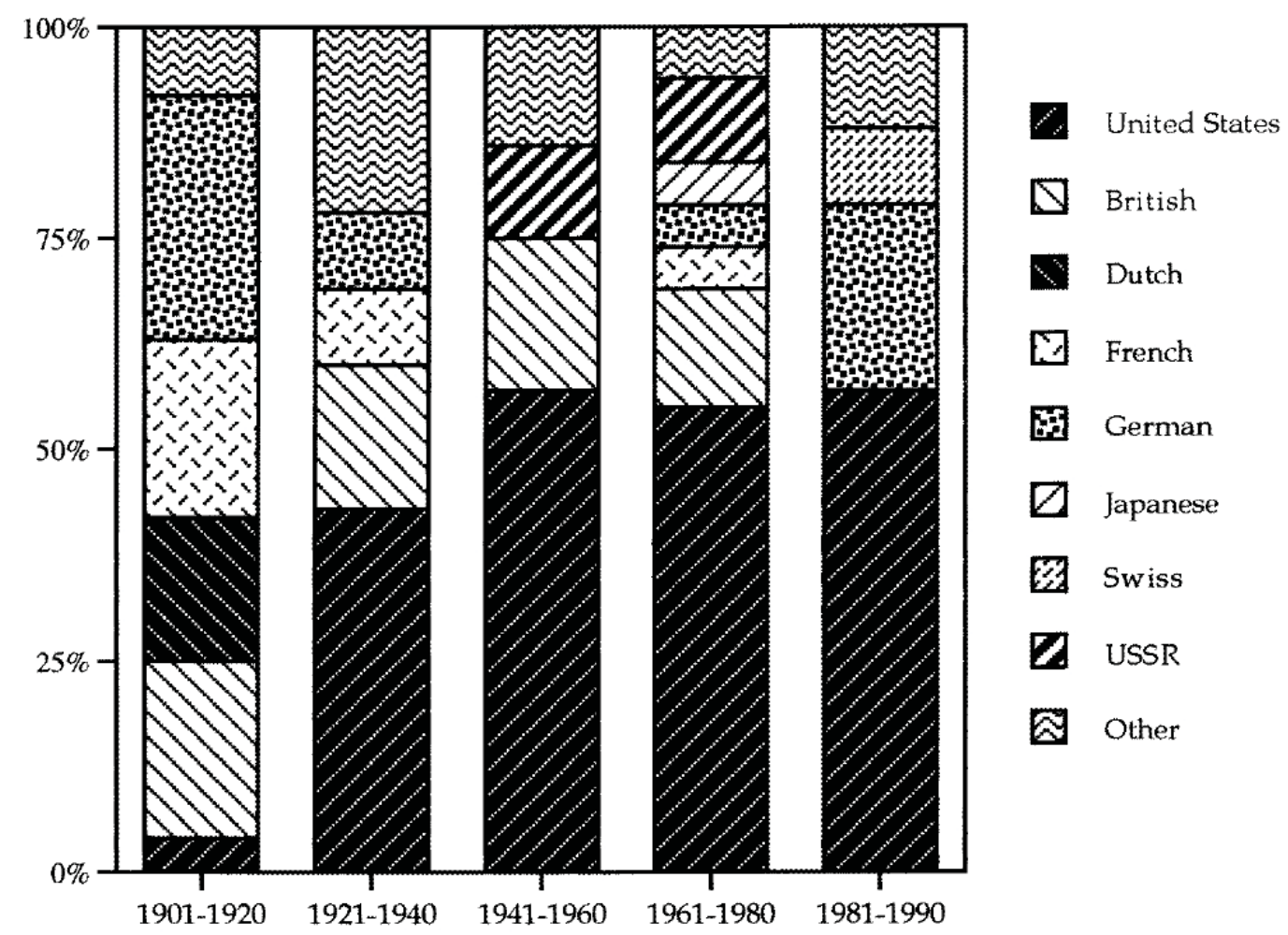

Figure 1. The nationality of laureates in different time periods from 1901 to 1990.

very important roles in shaping science policy and influencing science and technology education [3, 4]. Because of the history and influence of the Nobel prize, people are curious about the background, education and achievement of these laureates. For physics educators, the stories and anecdotes of Nobel laureates can add flavour to classroom lectures and may stimulate students' interest in learning the principles and methods of physics. Although there is abundant literature about Nobel laureates, demographic studies about Nobel prize winners in general and Nobel physics prize winners in particular are limited. In this paper, we systematically study the Nobel laureates in physics from 1901 to 1990 . The purpose of this study was threefold: firstly, to provide an overview of Nobel laureates in physics and present the data for educators to use in their teaching; secondly, to provide some results that may be significant enough for examination by those interested in the historical and social aspects of physics; and thirdly, to present some implications related to the current crisis in physics education.

\section{Methods}

We started our research by collecting data from various sources [5-7] and setting up an electronic database. Our database includes the names of the laureates, their award year(s), their nationalities, countries where they were born and educated, marital status, religious preference, research field, etc. Data concerning field of research and religion are more subjective and more difficult to judge than data concerning years and places. For laureates' research fields we went through the Nobel lectures and made the best judgment about what major work led to the award. We then compared the research work presented in the lecture with the Physics and Astronomy Classification Scheme (PACS) produced by the American Institute of Physics [8] and assigned a code to it for further analysis. In the case of any uncertainty about how to classify a research work, we consulted with other physicists and made a best judgment. The religious belief is an even harder determination. At this stage, 


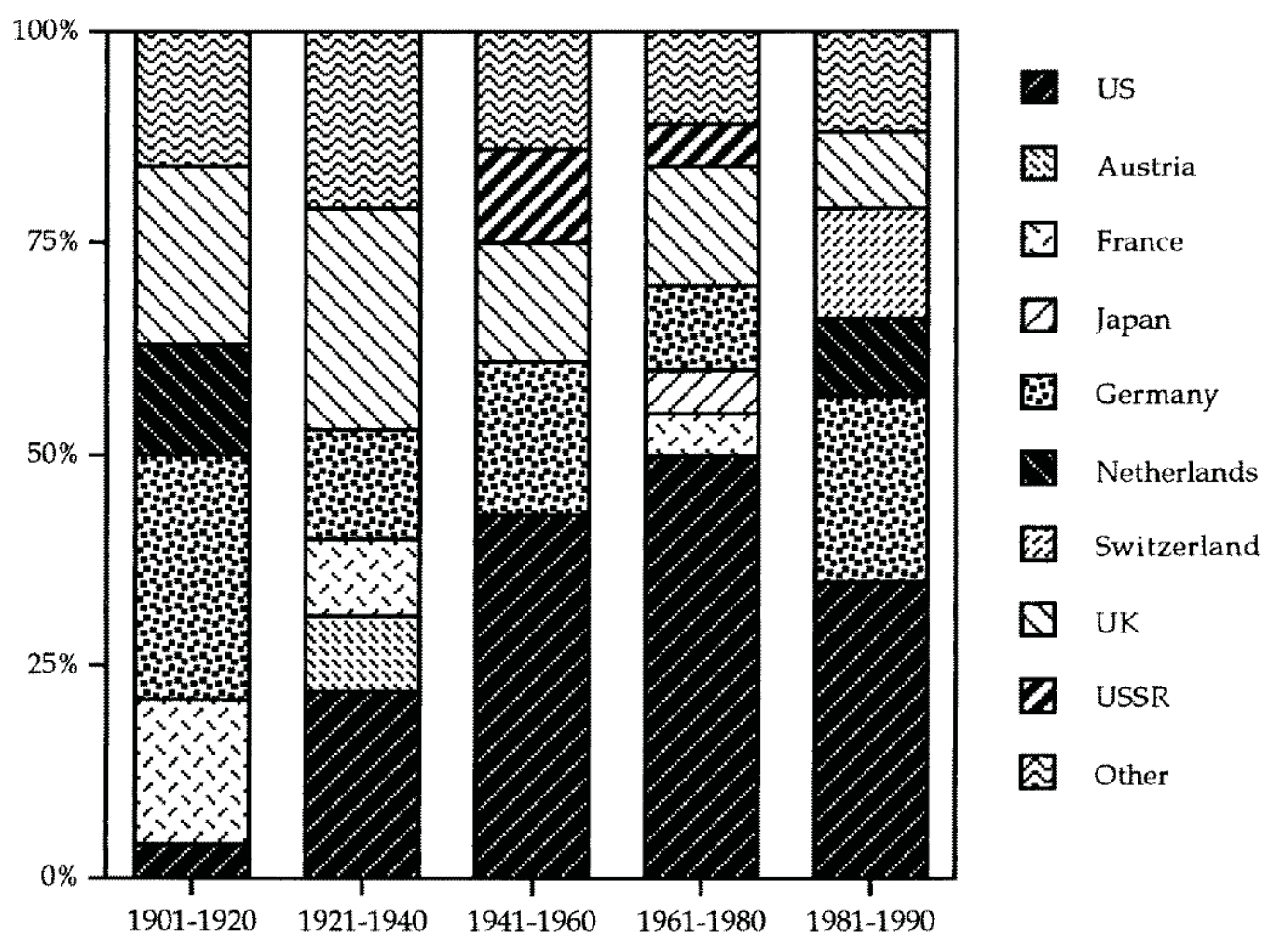

Figure 2. Countries where laureates got their final degree.

we used the data given in one source [5]. After setting up a database in a spreadsheet program, we analysed the data and created some graphs to visualize the results.*

\section{Results and analyses}

\section{Country of origin of laureates}

The nationalities of the prize winners and the countries where the laureates received their final education are shown in figures 1 and 2.

Between 1901 and 1920, Europeans dominated physics research. All the laureates during this period were born in Europe and all of them except A A Michelson (the winner in 1907) were educated in Europe. Of the 23 laureates in this period, 32\% were born and educated in Germany. Other countries that produced the laureates were Britain, Neth-

* The database is available as a Macintosh Excel file to those who are interested in obtaining a copy. erlands and France. Hence we can say that Europe was the centre of research and education in physics before 1920 .

During the 1920s and 1930s, our data show that the centre of physics education and research began to shift from Europe to America. Many prizes went to physicists born and educated in the USA and those who immigrated to the USA. During this period, $21 \%$ of the laureates were born and educated in the USA, and $42 \%$ had USA nationality. On the other hand, $17 \%$ were German-born physicists but only $8 \%$ had German nationality. Most laureates in this period were the elite that contributed dramatically to the developments of quantum mechanics and atomic physics.

Award of the Nobel prize was halted from 1940 to 1942 because of the Second World War (19391945). From 1943 to 1959, American physicists played the most important role in physics. Of 28 laureates in this period, 52\% had American nationality, including 30\% USA-born physicists and $22 \%$ immigrants. British physicists also had good 
performance during this period. Nineteen percent of laureates were British-born physicists and 15\% had British nationality. For the first time, Russian physicists began to take the prize. The number of German-born laureates decreased to $15 \%$, and the number of laureates that had German nationality decreased to only $4 \%$.

During the 1960s and 1970s, American physicists continued to dominate physics research. Of the 42 laureates* in this period, 57\% had USA nationality. From 1981 to 1990 , USA physicists received $60 \%$, while German physicists got $16 \%$ of the physics prizes.

Although there may be some political processes that affect the decision of the Nobel selection committee $[9,10]$, the Nobel prizes probably reflect the strength of a nation's science research in a particular area and period. Therefore, we can see that early in this century Europe dominated physics education and research. During the 1920s and 1930s the United States began to catch up with Europe and surpass it in the latter half of this century. Einstein [11] explained the success of scientific research in the United States as follows: "I have warm admiration for American institutes of scientific research. We are unjust in attempting to ascribe the increasing superiority of American research work exclusively to superior wealth; devotion, patience, a spirit of comradeship, and a talent for cooperation play an important part in its success."

\section{Ages and laureates}

It has been shown that, on average, physicists received the Nobel prize at an earlier age than researchers in other fields like chemistry or medicine, from 1901 to 1950 [12]. Our investigations show that there is a wide distribution of awards to laureates of different ages (figure 3 ).

A physicist can never be too young (W L Bragg got the prize at age 25) or too old (P L Kapitsa, age 84 ) to get the highest prize in physics. It can be seen from the figure that the great majority of the laureates got the prize between the ages of 35 and 65 . The likelihood of winning a Nobel prize in physics decreases sharply after a physicist reaches the age of 65 . We thought that it might be interesting to investigate the age when Nobel laureates actually did their prize-winning work; however, some re-

* J Bardeen was counted once.

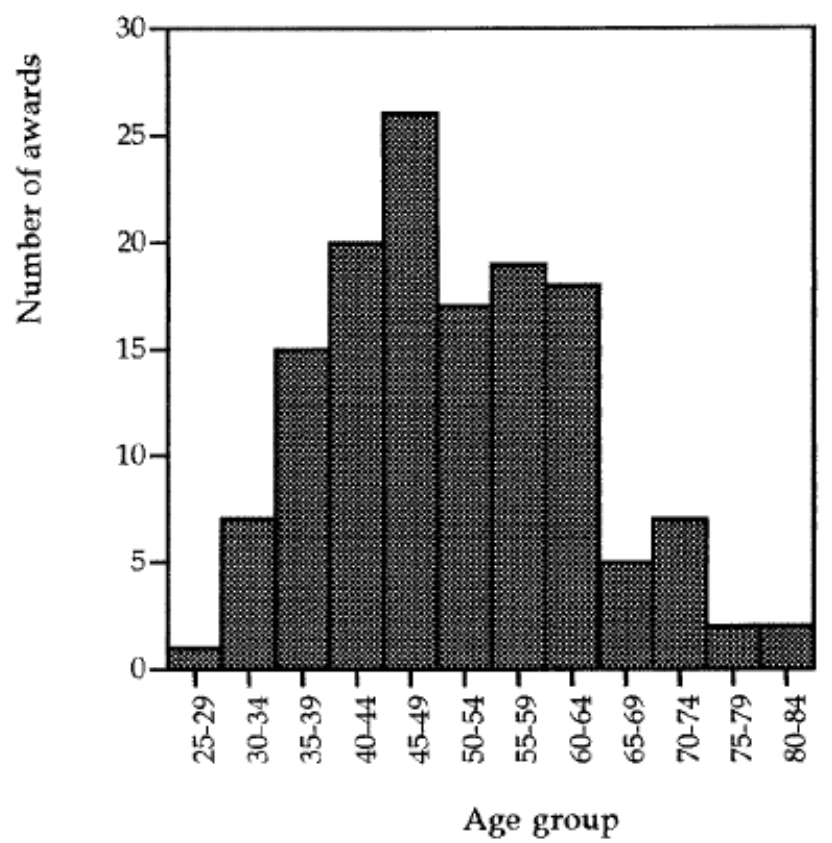

Figure 3. Distribution of award to laureates by age group.

searchers' publications span a large period of time and there is also the factor of the lag between the time of publication and the time when the work was done. We leave this analysis for future investigation.

\section{Religion and laureates}

There have been many times in history when discoveries in physics conflicted with religion, especially during the Middle Ages. The relation between science and religion has always been a sensitive and somewhat subjective issue prone to discussion and debate [13]. In this century, there have been some great discoveries, like relativity, quantum mechanics and the Big Bang theory, by Nobel laureates in physics which have affected humanity's view about the nature and origin of the universe. Therefore, Nobel laureates in physics, as a group of people working at the frontier of physics, are a population worth studying regarding the issue of religion and science.

Our statistics show that about $60 \%$ of the laureates had a Christian background. Twenty-four per cent of the laureates had a Jewish background, and $16 \%$ either had no affiliation or believed in other religions (figure 4).

One of the impressive results is that $24 \%$ of the physics laureates were Jewish or had a Jewish background. This result is consistent with the research 


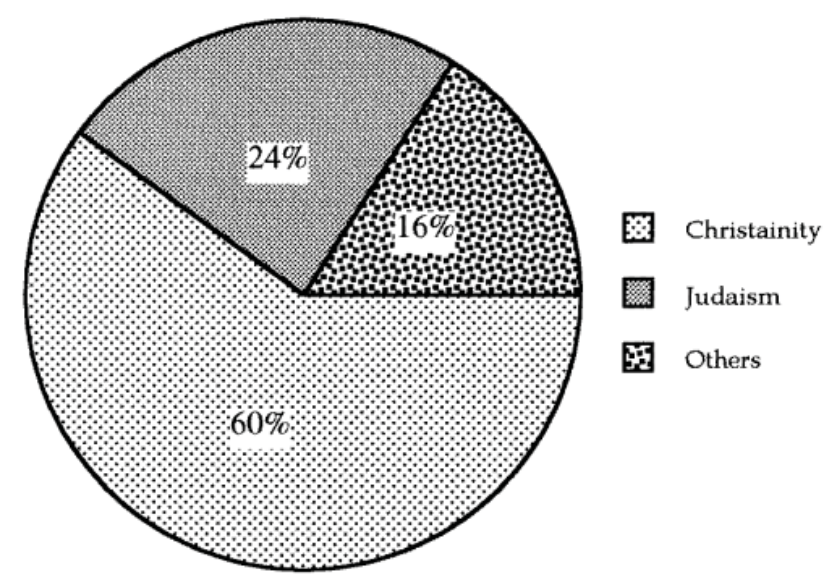

Figure 4. Laureates and religion.

carried out by Zuckerman [14] about American Nobel prize winners from 1901 to 1972 . Considering the comparatively small population of Jewish people, it can be said that Jewish physicists have contributed tremendously to the development of physical science. Therefore, it may be important for researchers who are interested in the ethnic aspects of physics education to study the influence of the Jewish family and community on Jewish physicists.

\section{Cooperation and laureates}

According to the Code of Status of the Nobel Foundation, one prize may be divided between two works or shared by two or more persons. The study of the Nobel physics prizes awarded to the number of laureates shows a clear trend. There has been a decrease in the number of prizes awarded to just one laureate (figure 5). In the early years, physics research seems to have been carried out on a much smaller scale and in a less cooperative way. One person could make a great discovery by working individually. The nature of science research changed during and after the Second World War. Big Science that requires a large amount of funding and largescale cooperation became the mainstream of physics research. This led to the decrease in the number of awards to one individual. From 1901 to 1990 , the number of prizes awarded to one individual decreased from $71 \%$ to $9 \%$.

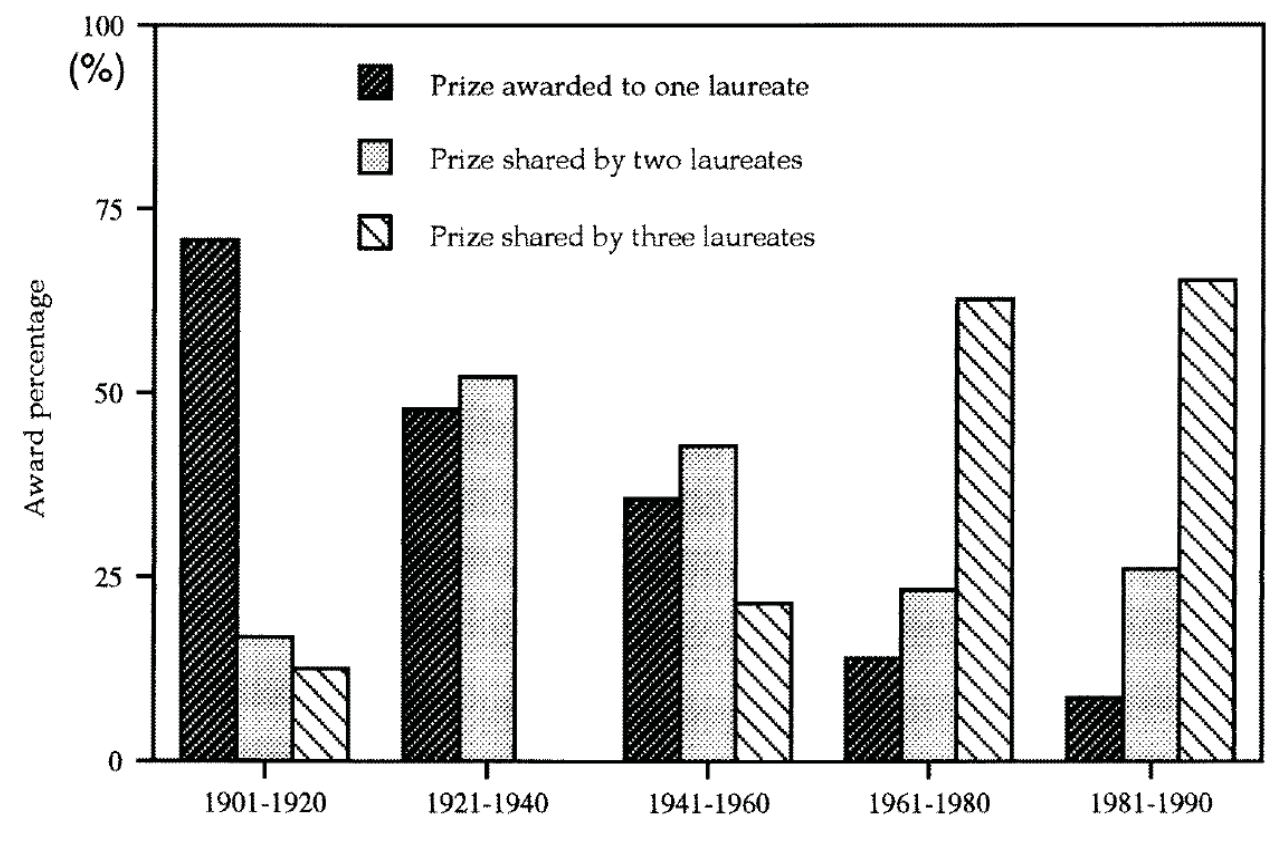

Time period

Figure 5. Percentage of laureates who got the prize individually or shared with others. 


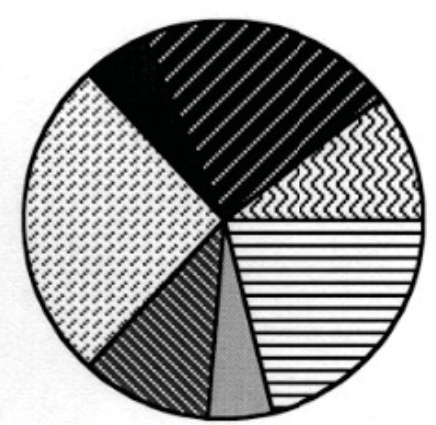

1901-1920

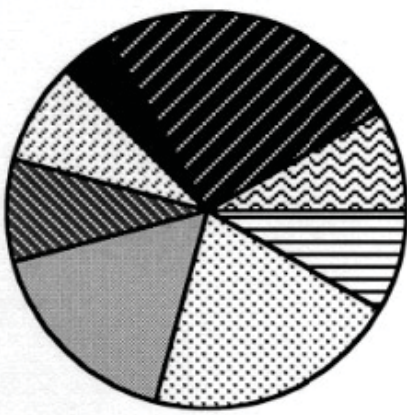

1961-1980

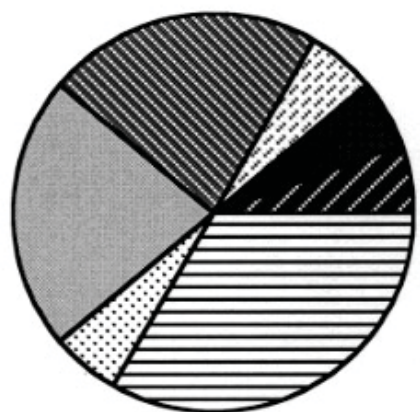

1921-1940

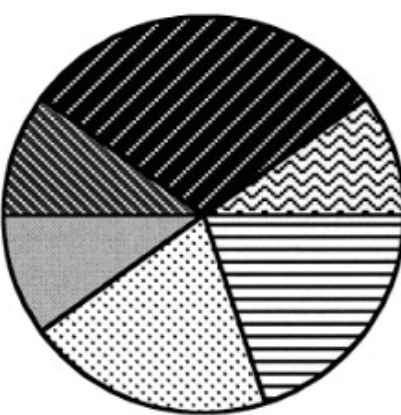

1981-1990

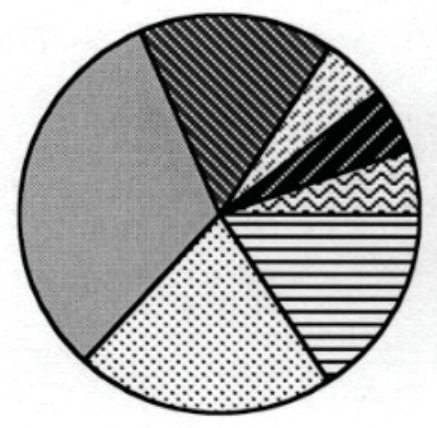

1941-1960
C00 General

C20 Nuclear Physics

C40 Fundamental Phenomenology

C60-C70 Condensed Matter

C90 Geophysics, Astronomy, and Astrophysics

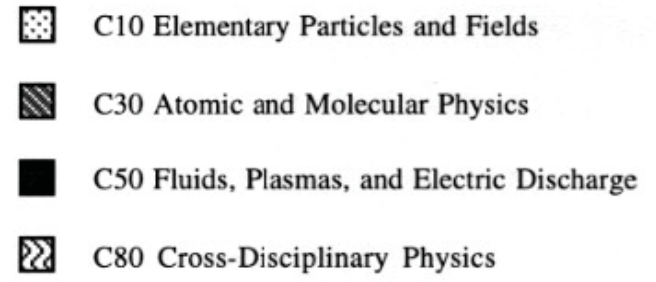

22 C80 Cross-Disciplinary Physics

Figure 6. Pie charts showing the relative number of prizes awarded in different subfields of physics during the different time periods from 1901 to 1990.

\section{Research and laureates}

As the Nobel physics prize is intended to be an award to "the person who shall have made the most important discovery or invention in the domain of Physics," an investigation of the research field receiving the award gives us a glimpse into the development of modern physics in this century (figure 6). The general aspect of physics as classified by PACS includes theories like quantum mechanics and relativity as well as instrumentation of general use. From 1901 to 1920, physics in general, fundamental phenomenology and early condensed matter physics (crystallography) were the focus of the award. From the 1920s came the development of atomic physics and nuclear physics. During the 1940s and 1950s, elementary particles and fields became a major field of study. With the discovery of semiconductors, superconductors and new functional materials, condensed matter physics has been awarded heavily since the 1950s. During the 1980s, elementary particles and fields as well as condensed matter physics were the main areas where the prize went. Since the peak years of the 1940s and 1950s, nuclear physicists have steadily decreased among the Nobel laureate population. 
Table 1. Some interesting information about Nobel prize winners in physics from 1901 to 1990.

\begin{tabular}{|c|c|c|c|c|}
\hline The first and the most & Name & $\begin{array}{l}\text { Award } \\
\text { year }\end{array}$ & $\begin{array}{l}\text { Research } \\
\text { field }\end{array}$ & Remarks \\
\hline $\begin{array}{l}\text { The first Nobel prize } \\
\text { winner in physics }\end{array}$ & Wilhelm Röntgen & 1901 & X-ray & Discovered $\mathrm{x}$-rays \\
\hline The youngest winner & William Bragg & 1915 & $\begin{array}{l}\text { X-ray } \\
\text { diffraction }\end{array}$ & $\begin{array}{l}\text { Awarded Nobel } \\
\text { prize at age } 25\end{array}$ \\
\hline $\begin{array}{l}\text { The laureate with the } \\
\text { lowest degree }\end{array}$ & Guglielmo Marconi & 1909 & $\begin{array}{l}\text { Wireless } \\
\text { telegraph }\end{array}$ & No advanced degree \\
\hline The first female laureate & Marie Curie & 1903 & Radiation & $\begin{array}{l}\text { The other female laureate } \\
\text { was Maria Mayer of } 1963\end{array}$ \\
\hline The oldest prize winner & Pyotr Kapitsa & 1978 & Low temperature & $\begin{array}{l}\text { Awarded Nobel prize } \\
\text { at age } 84\end{array}$ \\
\hline The oldest $\mathrm{PhD}$ & $\begin{array}{l}\text { Arno Penzias } \\
\text { Norman Ramsey }\end{array}$ & $\begin{array}{l}1978 \\
1989\end{array}$ & $\begin{array}{l}\text { Big bang } \\
\text { Atomic physics }\end{array}$ & Awarded $\mathrm{PhD}$ at age 39 \\
\hline $\begin{array}{l}\text { The laureate who died } \\
\text { at the earliest age }\end{array}$ & Pierre Curie & 1903 & Radiation & Died at age 47 \\
\hline
\end{tabular}

"Towards the end of the nineteenth century classical physics had reached a certain measure of completion, and some people were inclined to maintain that on the whole nothing remained for future generations of investigators but to fill in a few details here and there" [2, p 389]. However, this century's physics development turned out to be the most productive in history. Newtonian physics was challenged by relativity and quantum mechanics. Many new physics fields evolved with the development of new technologies and theories. As we are now again near the end of a century, will the next century's physics investigators have nothing to do but to fill in a few details here and there?

\section{Implications for physics education}

Our results may have implications for physics education in the following areas.

- Emphasize teamwork and cooperation. Modern physics research demands more cooperation between individuals. Heilbron [15] pointed out that, with the coming of Big Science, cooperation has become a new virtue distinct from the qualities of a "truly artistic style" and a "craving for solitude" shown by earlier physicists. Teamwork has become an indispensable constituent of a big scientist's creativity. Our statistical results agree with Heilbron's assertion by showing that the propor- tion of prizes awarded to an individual has been decreasing continually. This suggests that teamwork and discussion in physics classes should, perhaps, be emphasized more. Physics students need to be able to work on projects that require them to derive conclusions while collaborating with other people.

- Increase family influence. Recent social development has speeded up the alienation of families from educational systems. Many people place the blame solely on schools when children do not perform satisfactorily in learning science. This could have a large negative impact on the making of good scientists. The successes of Nobel laureates are inseparable from family influence. Dehmelt, laureate of 1989, described the support of his father in the following way: "I supplemented the school curriculum with do-it-yourself radio projects until I had hardly any time left for my classwork. Only tutoring from my father rescued me from disaster." Wilson, laureate of 1982, described his experience as: "I remember working on symbolic logic with my father; he also tried, unsuccessfully, to teach me group theory. I found high school dull." Parents of Nobel laureates in physics frequently served as financial providers, tutors, mentors and colleagues. $\mathrm{K} M$ Siegbahn, laureate of 1981, once remarked on his father's influence, "It's a decided advantage if you start discussing physics every day at the breakfast table." It is not surprising that there are four pairs of father and son among the Nobel prize winners in 
physics from 1901-1990: J J Thomson (1906) and G P Thomson (1937); W H Bragg (1915) and W L Bragg (1915); N H D Bohr (1922) and A N Bohr (1975); K M G Siegbahn (1924) and K M B Siegbahn (1981).

- Stimulate interests in science. Nobel laureates in physics developed their interests in science at very early ages. Kendall, laureate of 1990, described his own experience this way: "I had developed - or been born with - an active curiosity and an intense interest in things mechanical, chemical and electrical and do not remember when I was not fascinated with them and devoted to their exploration." Rubbia, laureate of 1984, wrote: "As a boy, I was deeply interested in scientific ideas, electrical and mechanical, and I read almost everything I could find on the subject." Their interests in science were aroused or kept alive by making things and solving challenging problems rather than learning tedious theorems and proofs, as Binnig, laureate of 1986, described: "I realized that actually doing physics is much more enjoyable than just learning it. Maybe "doing it" is the right way of learning, at least as far as I am concerned." Many laureates had hobbies of making radio receivers, building model airplanes and doing chemical experiments in their mothers' kitchens in their childhood. Enthusiasm for sciences developed at an early age allowed them to be able to get to the front in spite of obstacles faced in their later scientific research.

Nobel laureates in physics are a special population selected from the scientific elite of this century. This century's Nobel laureates have not only contributed to society scientifically, but have also given us models in showing us how to learn, how to invent and how to create. For a teacher, having an overview of Nobel laureates in physics may help link the social side of science to the classroom and inspire a new generation of scientific intelligentsia.

\section{Acknowledgments}

The authors thank Ellen Weissinger, Edgar Pearlstein, Mark Clark, Sitaram Jaswal and Stephanie Snedden of the University of Nebraska-Lincoln, Richard Fuller of Gustavus Adolphus College, and Patrick Reany of Arizona State University for their helpful comments and suggestions.

\section{References}

[1] Crawford E 1984 The Beginnings of the Nobel Institute: The Science Prizes, 1901-1915 (New York: Cambridge University Press) pp 221-9

[2] Siegbahn M and Siegbahn K 1972 The physics prize Nobel: The Man and His Prizes 3rd edn, ed Nobel Foundation and W Odelberg (New York: American Elsevier) pp 619-37

[3] Dickson D 1988 An “Intellectual Summit” Science 239 459

[4] Cooke D 1990 Teaching teachers: a Nobel laureate's plan for improving science education Scientific American 263 (4) 34

[5] Schlessinger B S and Schlessinger J H (ed) 1990 The Who's Who of Nobel Prize Winners (Oryx Press)

[6] Nobel Lectures: Physics. Vol 1 (1901-1921), Vol 2 (19221941), Vol 3 (1942-1962) (Amsterdam: Elsevier, 1967)

[7] Frangsmyr $\mathrm{T}$ and Ekspong G (ed) 1993 Nobel Lectures: Physics 1981-1990 (Singapore: World Scientific)

[8] The Physics and Astronomy Classification Scheme can be found in Phys. Rev. Lett. 70 (8) i-xix (1993)

[9] MacLachlan J 1991 Defining physics: the Nobel Prize selection process, 1901-1937 Am. J. Phys. 59 166-74

[10] Crawford E 1992 Nationalism and Internationalism in Science, 1880-1939 (Cambridge: Cambridge University Press) pp 54-78

[11] Einstein A 1954 Ideas and Opinions (New York: Bonanza Books) pp 6-7

[12] Manniche E and Falk G 1957 Age and the Nobel Prize Behav. Sci. 2 301-7

[13] Barbour I 1990 Religion in an Age of Science (San Francisco: Harper \& Row) pp 3-28; Selk E 1991 Religion in an age of science (book review) Am. J. Phys. 59 1152-3; Orear J 1992 Religion vs science? Am. J. Phys. 60394 ; Dotsor A 1992 A response to "religion vs science?" Am. J. Phys. 60778

[14] Zuckerman H 1977 Scientific Elite (New York: The Free Press) pp 68-82

[15] Heilbron J 1992 Creativity and big science Phys. Today November, 42-7

Submitted June 1997; revised November 1997. 